\title{
Improving Emergency Response Systems in the Oil and Gas Industry To Reduce Environmental Damage
}

\author{
$A$ Kostyuk $^{1}, A$ Tumanov $^{1}, V$ Tumanov $^{1 \varpi}$ and $O$ Zybina $^{2}$ \\ ${ }^{1}$ Peter the Great St.Petersburg Polytechnic University, 195251 St. Petersburg, Russia \\ ${ }^{2}$ National Technology Initiative Center for Advanced Manufacturing Technologies based on the \\ Institute of Advanced Manufacturing Technologies of Peter the Great St. Petersburg Polytechnic \\ University Polytechnicheskaya, 29, St.Petersburg, 195251, Russia
}

\begin{abstract}
The article identifies the main problems of eliminating the reduction of environmental damage by improving the response systems to man-made accidents at hazardous production facilities of the oil and gas complex. Risk factors for ensuring safety at a hazardous production facility in the oil and gas industry are identified, the most significant risk factor is identified by the method of hierarchical analysis, and the problem of the engineering and technical factor in the system "man - technical environment - industrial environment - environment" is revealed. "The solution to the problem is indicated - the use of a developed mobile emergency response system, which makes it possible to halve the response time to an emergency. The developed response system can be applied at any hazardous production facility in the oil and gas industry due to its flexibility.
\end{abstract}

Keywords: Risk, environmental damage, emergency response, risk management, risk factors, mobile emergency response system

\section{Introduction}

One of the main parts of the Russian economy is the oil and gas industry, which ensures the functioning of other industries and the well-being of our population. When operating hazardous production facilities in the oil and gas industry, there is always the possibility of accidents.

According to Federal service for environmental, technological and nuclear supervision, over the past 10 years, the main causes of accidents were technical and organizational factors.

In December 2019, preliminary results of economic damage from accidents at Russian oil and gas facilities were summed up at the conference "Industrial safety and labor protection at oil and gas enterprises".

\footnotetext{
*Corresponding author: toumanov@mail.ru
} 
According to the calculations of the head of the Department for supervision of oil and gas facilities - Yuri Nesterov, the economic damage from accidents exceeded 1 billion 405 million rubles. In total, 37 accidents occurred at oil and gas industry facilities in 2019, seven of which resulted in group accidents or worker deaths. Emergency incidents were recorded at the facilities of the following companies - "TAAS-Yuryakh Neftegazodobycha", "TEX-TRO", "SIBUR-Kstovo", "RUSENERGO", "Nizhnekamskneftekhim" and "Transbunker-Vanino".

\section{Materials and Methods}

When analyzing the response to emergency situations, the following shortcomings were identified:

- insufficient speed of informing about the emergency,

- making decisions on elimination and localization of emergency situations at remote sites,

- poor management in emergency response planning.

The article considers the specifics of emergency response at hazardous production facilities in the oil and gas industry.

The main causes of possible incidents and accidents are:

1. equipment failure (hazards associated with typical processes),

2. erroneous actions of personnel (production hazards caused by violations of equipment operation, violations of fire safety and labor protection rules by employees),

3. external impacts of natural and man-made nature.

This distribution of causes into groups is conditional, because they are often intertwined, summed up, or have other complex connections [1].

To eliminate and localize an emergency that has occurred for any of the above reasons, various types of units are involved [1]. The success of elimination and localization of accidents directly depends on the efficiency of notification of all internal and external departments, as well as actions taken by them in the first few minutes after the occurrence of an emergency [2].

Therefore, the solution to the problems of emergency response in the oil and gas complex was chosen to improve the emergency response systems in the oil and gas complex by creating a mobile emergency response system that reduces the response time, which minimizes material and environmental damage, as well as damage that can be caused to the engineering and technical complex.

Reducing the response time to emergency situations in the system "human-technical environment-production environment" should occur in a comprehensive manner, including various risk factors.

Risk factors are conditions that increase the likelihood of an emergency or emergency at work. Their identification consists in systematic identification of risks and determination of their characteristics.

Risk factors are conditions that increase the likelihood of an emergency or emergency at work. Their identification consists in systematic identification of risks and determination of their characteristics.

According to GOST R 51897-2011 " Risk management. Terms and definitions " risk identification refers to the process of identifying, listing and describing risk elements.

At the stage of identification of risk factors were identified: 
1) sources of possible incidents and accidents related to the destruction of structures and (or) technical devices at the OPO, uncontrolled releases and (or) explosions of dangerous substances (table 1),

2) the main (typical) accident scenarios, taking into account their consequences, while considering the initiating and subsequent events that lead to the possible occurrence of damaging factors of accidents (table 2).

Table 1. Sources of possible incidents and accidents at hazardous production facilities in the oil and gas industry.

\begin{tabular}{|c|c|}
\hline Source & Characteristic \\
\hline $\begin{array}{l}\text { Equipment } \\
\text { failure }\end{array}$ & $\begin{array}{l}\text { - Physical wear, metal fatigue, welding failure, mechanical damage, } \\
\text { corrosion. } \\
\text { After analyzing the problems and emergencies, we can conclude that } \\
\text { the destruction of equipment and pipelines due to metal corrosion is often } \\
\text { local and does not lead to serious consequences. But it is important to note } \\
\text { that in the absence of a timely response, further development of the } \\
\text { accident may occur. } \\
\text { - The failures, the destruction and breakdown of equipment. } \\
\text { Main equipment failures/failures: failure of the grounding system, } \\
\text { protection from static electricity; rupture or violation of the tightness of the } \\
\text { deployed pipeline network, which can lead to the release of petroleum } \\
\text { products, failure of pumping units as a result of the destruction of support } \\
\text { bearings, shaft, seal depressurization; failure/failure of electrical } \\
\text { equipment, wiring. }\end{array}$ \\
\hline $\begin{array}{c}\text { External } \\
\text { impacts of } \\
\text { natural and } \\
\text { man-made } \\
\text { nature }\end{array}$ & $\begin{array}{l}\text { - Discharge of atmospheric electricity, possible when an object is struck } \\
\text { by lightning; } \\
\text { Defeat is possible when two events interact-a direct lightning strike and } \\
\text { zero operation of the lightning rod (due to absence, incorrect design or } \\
\text { malfunction). } \\
\text { - Adverse weather conditions; } \\
\text { Strong wind (speed at gusts of } 25 \mathrm{~m} / \mathrm{s} \text { or more), heavy ice (deposits on } \\
\text { wires with a diameter of } 20 \mathrm{~mm} \text { or more), a strong snowstorm combined } \\
\text { with a strong wind speed of } 15 \mathrm{~m} / \mathrm{s} \text { or more, which can cause accidents on } \\
\text { power networks and lead to interruptions in power supply. The frequency } \\
\text { of adverse weather conditions varies depending on the climatic conditions } \\
\text { in which the object is located. } \\
\text { - Earthquakes, landslides, mudslides, avalanches. } \\
\text { - Falling of an airplane, meteorite, etc. } \\
\text { The frequency of this event does not exceed } 1 \times 10^{-6} 1 / \text { year. } \\
\text { - Sabotage and terrorist acts, acts of vandalism. } \\
\text { The frequency does not exceed } 1 \times 10^{-6} 1 / \text { year. }\end{array}$ \\
\hline $\begin{array}{l}\text { Erroneous } \\
\text { actions } \\
\text { of the staff }\end{array}$ & $\begin{array}{l}\text { - Production hazards caused by violations of fire safety and labor } \\
\text { protection rules by employees. } \\
\text { The reasons for these hazards may be personnel error during sampling, } \\
\text { violation of fire safety and/or labor protection instructions, unauthorized } \\
\text { use of equipment after repair, start-up of equipment without crimping, use } \\
\text { of equipment before Troubleshooting, operation of equipment with the } \\
\text { monitoring and control system disabled, etc. } \\
\text { - Violations of equipment operation. }\end{array}$ \\
\hline
\end{tabular}


Table 2. Typical accident scenarios considering their consequences.

\begin{tabular}{|c|c|}
\hline $\begin{array}{l}\text { The scenario of } \\
\text { an emergency }\end{array}$ & Result of an emergency \\
\hline $\begin{array}{l}\text { The fire of the } \\
\text { strait }\end{array}$ & $\begin{array}{l}\text { Complete (partial) destruction of equipment }->\text { discharge of a } \\
\text { dangerous substance }+ \text { ignition source }->\text { formation of a Strait fire }-> \\
\text { thermal damage to people, structures and equipment, environmental } \\
\text { pollution }\end{array}$ \\
\hline $\begin{array}{l}\text { Explosion of a } \\
\text { cloud of fuel-air } \\
\text { mixture }\end{array}$ & $\begin{array}{l}\text { Complete (partial) destruction of equipment }->\text { outflow of a } \\
\text { dangerous substance (flammable liquid, flammable gas) }-> \\
\text { (evaporation of flammable liquid) }->\text { formation of a cloud from the } \\
\text { fuel-air mixture }->\text { spread of the fuel-air mixture cloud }+ \text { ignition } \\
\text { source }->\text { explosion of the fuel-air mixture cloud (possible fire spillage) } \\
->\text { baric and thermal damage to people, structures and equipment, } \\
\text { environmental pollution }\end{array}$ \\
\hline Flare burning & $\begin{array}{l}\text { Complete / partial destruction of equipment or depressurization of a } \\
\text { gas pipeline, a high-pressure container with flammable gas }->\text { outflow } \\
\text { of the gas mixture }+ \text { ignition source }->\text { gas ignition (formation of a } \\
\text { flare) }->\text { thermal damage to people, structures and equipment }-> \\
\text { formation and spread of a cloud of combustion products, environmental } \\
\text { pollution }\end{array}$ \\
\hline
\end{tabular}

Thus, the following risk factors were identified by analyzing the available information:

1) socio-psychological,

2) engineering and technical,

3) technological,

4) natural and geographical,

5) organizational and structural.

Among the identified risk factors of the "human - technical environment" system production environment" according to the research on the method of analyzing hierarchies in the dialog system "MPRIORITY 1.0" using the Saati matrix, the most significant factor was engineering and technical (figure 1), so reducing the response time to emergencies should using modern communication tools and technologies (the factors were compared with each other in terms of their impact on response time, response adequacy (correct decision making), monitoring, management efficiency, and the cost of converting the factor).

Thus, the following risk factors were identified by analyzing the available information:

1) socio-psychological,

2) engineering and technical,

3) technological,

4) natural and geographical,

5) organizational and structural.

Among the identified risk factors of the "human - technical environment" system production environment" according to the research on the method of analyzing hierarchies in the dialog system "MPRIORITY 1.0" using the Saati matrix, the most significant factor was engineering and technical (figure 1), so reducing the response time to emergencies should using modern communication tools and technologies (the factors were compared with each other in terms of their impact on response time, response adequacy (correct decision making), monitoring, management efficiency, and the cost of converting the factor). 


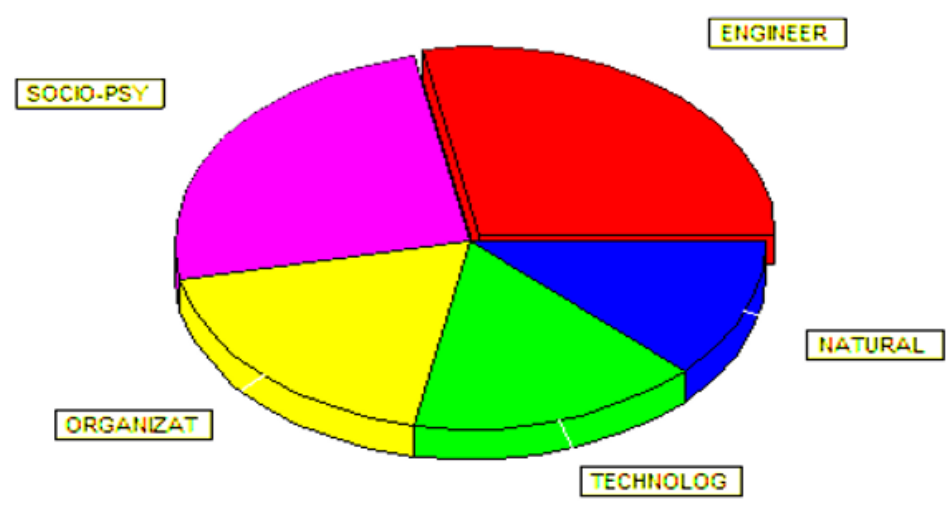

Fig. 1. The final result of the prioritization between risk factors.

Introduction of modern means of communication in the mobile response system contributes to the rapid adoption of effective measures to localize accidents and prevent its development in an adverse scenario. Today, new generation HSPA and LTE communication networks are actively developing. HSPA (High Speed Packet Access) is a high - speed data transfer. HSPA+ allows you to achieve speeds up to $42.2 \mathrm{Mbit} / \mathrm{s}$ and returns up to $5.76 \mathrm{Mbit} / \mathrm{s}$.

LTE (Long-Term Evolution) - 4th generation data transfer technology transmits data over a wireless mobile network at speeds up to $299.6 \mathrm{Mbit} / \mathrm{s}$ per download and up to 172.8 $\mathrm{Mbit} / \mathrm{s}$.

In Russia, a full-fledged $5 \mathrm{~g}$ launch is planned in 2022. The 5G network is the 5th generation of mobile communications. The record speed is $35 \mathrm{Gbit} / \mathrm{s}$. The available frequencies will be determined by the government of the Russian Federation by the end of the current (2020) year.

Every year, data transfer capabilities are growing. This indicates the relevance of using modern communication technologies to respond to emergencies.

The development of the mobile network gives new prospects for the use of communications and mobile devices. It is possible to solve problems of uploading data to and from the network for industrial purposes.

Years ago, this solution was not possible due to the low resistance of tablet PCs to low temperatures, insufficient impact resistance and moisture resistance.

The latest tablet PCs have the necessary properties-a frost-resistant battery and a high degree of protection. In 2014, Samsung presented the first tablets designed for industrial use at the fourth international gas forum in Saint Petersburg.

Tablet PCs have a diagonal of 7 to 10 inches, a shock-resistant case that can withstand the fall of a load weighing up to $5 \mathrm{~kg}$ from the height of a five-story building, they also have high moisture resistance and can work at temperatures below $-28^{\circ} \mathrm{C}$. At the same time, the company plans to improve its performance over time.

Sony presented advanced developments in the field of video surveillance. The cameras have high impact resistance, frost resistance and image transmission quality.

Using these means of communication and technologies, the scheme of notification and response to emergency situations in the oil and gas complex looks as follows (figure 2). 


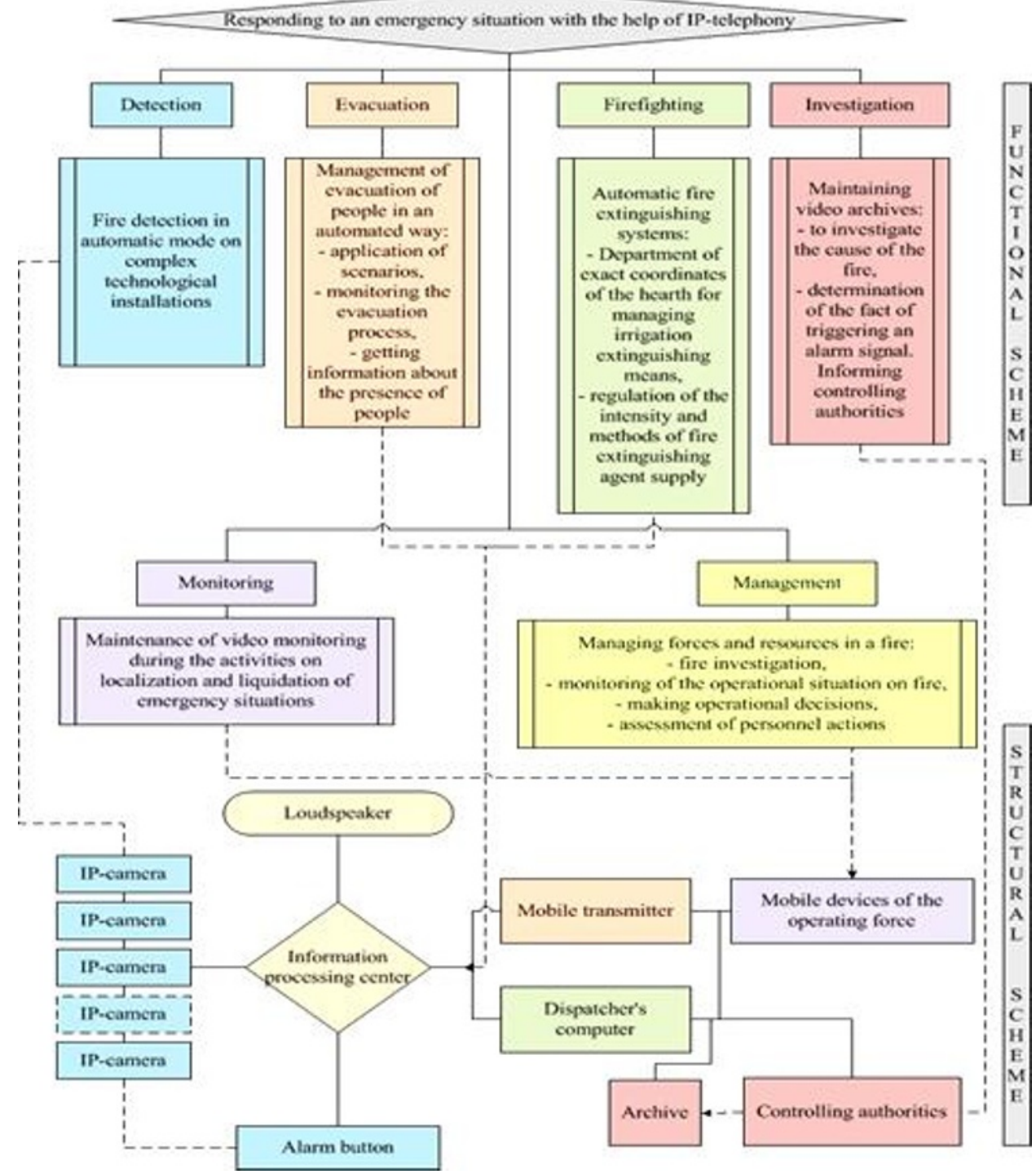

Fig 2. Functional and structural scheme of emergency response of the proposed mobile response system.

If an alarm signal is received, the alarm is triggered and automatically all devices of the members of the operational Commission for emergency situations and fire safety and the dispatcher service receive a call that connects them to each other in video conferencing mode and outputs images from video cameras.

Members of the Commission discuss the visualized situation, can make decisions on the response and communicate it to the staff using installed loudspeakers.

As a result of the proposed system, the time for visualization of an emergency situation is reduced, which gives the following opportunities:

- rapid assessment of the emergency scenario,

- monitoring the notification system,

- evaluating the effectiveness of actions performed, 
- discussing and making urgent decisions,

- monitoring the situation;

- operational management of forces and means.

To implement the system, you must:

- provide the operational group of the Commission on emergency situations with modern means of communication that can use ip-telephony,

- provide high-speed Internet access to the object,

- install ip cameras on the object that can output images to the network and mobile devices,

- combine the existing system with the proposed one so that when the alarm button is pressed, an alarm is automatically triggered and a call is made to all the devices of the Commission members and the dispatcher service, connecting them in video conferencing mode and displaying images from cameras,

- coordinate the use of the system with the Supervisory authorities,

- connect staff mobile devices to speakers,

- organize measures to ensure information security at a dangerous production facility.

Implementation of the system on the site should be carried out with the development of the necessary project documentation and introduction into all internal production instructions. Staff should be trained in the use of the system.

The system has flexibility that allows you to adjust its parameters (the number of cameras, mobile devices, etc.) to any dangerous production facility.

The proposed mobile emergency response system significantly reduces the response time.

The time of free development of an emergency situation consists of:

$\mathrm{T}_{\mathrm{d}}$ - detection time,

$$
\mathrm{T}_{\mathrm{fd}}=\mathrm{T}_{\mathrm{d}}+\mathrm{T}_{\mathrm{m}}+\mathrm{T}_{\mathrm{j}}+\mathrm{T}_{\mathrm{c} / \mathrm{d}}
$$

$\mathrm{T}_{\mathrm{m}}$ - time of the message,

$\mathrm{T}_{\mathrm{j}}$ - journey time,

$\mathrm{T}_{\mathrm{c} / \mathrm{d}}$ - time of combat deployment.

Based on calculations according to the calendar plan of operational measures in case of emergencies, the leading Russian oil and gas companies (table 3, table 4):

$\mathrm{T}_{\mathrm{d}} \approx 43 \%$ of the total time of free development of the emergency situation,

$\mathrm{T}_{\mathrm{m}} \approx 14 \%$ of the total time of free development of the emergency situation,

$\mathrm{T}_{\mathrm{j}} \approx 29 \%$ of the total time of free development of the emergency situation,

$\mathrm{T}_{\mathrm{c} / \mathrm{d}} \approx 14 \%$ of the total time of free development of the emergency situation.

Table 3. Calendar plans of operational measures in case of an emergency before the implementation of the proposed system.

\begin{tabular}{|c|c|}
\hline Measure & Execution time \\
\hline $\begin{array}{c}\text { Notification and gathering of the management staff and members } \\
\text { of the commission }\end{array}$ & 1 hour 30 minutes \\
\hline $\begin{array}{c}\text { Arrival of the commission's working group and emergency rescue } \\
\text { units during working hours }\end{array}$ & 3 hours \\
\hline $\begin{array}{c}\text { Arrival of the commission's working group and emergency } \\
\text { rescue units outside working hours }\end{array}$ & 4 hours \\
\hline \begin{tabular}{c} 
Organization of round-the-clock duty \\
\hline
\end{tabular} & Constantly \\
\hline
\end{tabular}


Departure of the commission's task force to the emergency zone Organization of protection of the emergency zone, ensuring the delivery of emergency rescue units of special equipment and means
$30 \min -2$ hours

2 hours 30 minutes

Table 4. Calendar plans of operational measures in case of an emergency after the implementation of the proposed system.

\begin{tabular}{|c|c|}
\hline Measure & Execution time \\
\hline $\begin{array}{c}\text { Notification and gathering of the management staff and } \\
\text { members of the commission }\end{array}$ & 30 minutes \\
\hline $\begin{array}{c}\text { Arrival of the commission's working group and emergency } \\
\text { rescue units during working hours }\end{array}$ & 1 hour \\
\hline $\begin{array}{c}\text { Arrival of the commission's working group and emergency } \\
\text { rescue units outside working hours }\end{array}$ & 2 hours \\
\hline $\begin{array}{c}\text { Organization of round-the-clock duty } \\
\text { zone }\end{array}$ & Constantly \\
\hline $\begin{array}{c}\text { Departure of the commission's task force to the emergency } \\
\text { Organization of protection of the emergency zone, ensuring } \\
\text { the delivery of emergency rescue units of special equipment and } \\
\text { means }\end{array}$ & 2 hours 30 minutes \\
\hline
\end{tabular}

In this way, the system can reduce the total time for notification and response to an emergency from 90 minutes to 45 minutes, which indicates its effectiveness. Also, the arrival of the Commission at a dangerous industrial facility for emergencies becomes less necessary.

\section{Results}

The mobile emergency response system requires special attention to information security. The process of organizing safe use prevents information leaks.

We need to consider a comprehensive solution that will include all organizational, technological and technical aspects.

There is also always a risk of unskilled actions by personnel using mobile devices. To minimize risks, it is necessary to take organizational and technical measures and solutions that will allow centralized management of personnel's mobile devices, as well as distinguish between rights and usage policies.

According to experts, the most significant risks are theft or loss of the device, as well as the connection of hackers. To minimize this risk, we recommend using MDM (Mobile Device Management).

In addition, the risk of staff neglecting the simplest rules for safe use of mobile devices follows. To minimize this risk, it is necessary to separate personal and corporate information and protect the latter by using software tools.

Due to user negligence, there may be threats related to viruses and Trojans. Mobile Device Management has the ability to centrally deploy antivirus SOFTWARE on company employees ' devices.

The company "Samsung" offers the following solutions:

SOTI Mobicontrol. This SOFTWARE is simple and easy to install and allows you to solve the following tasks:

- blocking the terminal service session, 
- data encryption and user identification policies provide reliable data protection.

The main features of this SOFTWARE are real-time remote monitoring, Troubleshooting, and device location detection.

This solution is the best choice for minimizing the operating costs of maintaining the mobile workplace segment.

\section{Discussion}

The results obtained in this work can be useful in improving response system in the oil and gas industry. In the future, it is possible to continue the study based on the results. The analysis of emergency situations shows that insufficient speed of informing about the emergency, making decisions on elimination and localization of emergency situations at remote sites and poor management in emergency response planning should be upgraded. The developed recommendations on the prevention of emergencies as a result of the study were discussed at a number of conferences.

\section{Conclusion}

Effective localization and elimination of accidents is possible only with the mobilization of all available resources and forces [2]. The main criterion for evaluating the effectiveness of emergency response is the speed [3], which can be achieved at any hazardous production facility in the oil and gas industry using the proposed mobile emergency response system. Reducing the response time allows you to reduce material and environmental damage, as well as damage that can be caused to the engineering complex.

\section{References}

1. Verslycke, T., Reid, K.: The Chemistry Scoring Index (CSI): A hazard-based scoring and ranking tool for chemicals and products used in the oil and gas industry. Sustainability (Switzerland) 6, 3993-4009. (2014).

2. Saling, P., Kicherer, A.: Eco-efficiency analysis by BASF: The method. International Journal of Life Cycle Assessment 7, 203-218. (2002).

3. Chen, X., Miao, Y.: A methodology for overall consequence assessment in oil and gas pipeline industry. Process Safety Progress 38. (2019).

4. Khan, F.I., Haddara, M.M.: Risk-based maintenance (RBM): A quantitative approach for maintenance/inspection scheduling and planning. Journal of Loss Prevention in the Process Industries 16, 561-573. (2003).

5. Brito, A.J., de Almeida, A.T. : Multi-attribute risk assessment for risk ranking of natural gas pipelines. Reliability Engineering and System Safety 94, 187-198. (2009).

6. Yuhua, D., Datao, Y.: Estimation of failure probability of oil and gas transmission pipelines by fuzzy fault tree analysis. Journal of Loss Prevention in the Process Industries 18, 83-88. (2005).

7. Erkut, E., Verter, V.: Modeling of transport risk for hazardous materials. Operations Research 46, 625-642. (1998).

8. Faber, M.H., Stewart, M.G.: Risk assessment for civil engineering facilities: Critical overview and discussion. Reliability Engineering and System Safety 80, 173-184. (2003).

9. Tumanov, A., Solovyov, A.: Development of the Theoretical-Practical Model of Protection of the Means of Transport of Radioactive Materials. IOP Conference Series: Earth and Environmental Science, vol. 459(3). (2020) 
10. Tumanov, A., \& Venevsky, S.: Elaboration of Theoretical Methods for Assessment of Isolated and Combined Physical Damage Effects of Technogenic Accident while Transporting Radiological Materials by Multimodal Transport. IOP Conference Series: Materials Science and Engineering, 582(1). (2019)

11. Tumanov, A., Monashkov, V.: Improving Training in the Field Safety Management and Protection in Emergency Situations. IOP Conference Series: Earth and Environmental Science, 459(3). (2020)

12. Tumanov, A., Ryabinina ,E.: Methodology for Evaluating a Prevented Damage in Accidents at Energy Saturated Objects. IOP Conference Series: Earth and Environmental Science, vol. 459(4). (2020)

13. Tumanov, V., Chibidin, A.: Physical characteristics of the thermal impact of an emergency fire. Journal of Physics: Conference Series, vol. 1614(1). (2020).

14. Kulikova, V. A., Yakovlev, V.: Remote radiation monitoring device. Journal of Physics: Conference Series, vol. 1614(1). (2020).

15. Tumanov, A.. Risk Assessment of Accidents during the Transportation of Liquid Radioactive Waste in Multimodal Transport. IOP Conference Series: Earth and Environmental Science, vol. 272(3). (2019).

16. Burlov, V., Mankov, M.: Safety management technology of electric networks using geo information system. In Advances in Intelligent Systems and Computing: Vol. 1259 AISC. (2021).

17. Tumanov, A., Sabanaev, A.: Statistical testing of hypotheses about the form of the factor law of influence by the Kolmogorov criterion. Journal of Physics: Conference Series, 1614(1). (2020).

18. P. Bolat, J. Yongxing, Risk assessment of potential catastrophic accidents for transportation of special nuclear materials through Turkish Straits. Energy Policy. 56, 126-135 (2013).

19. Bolat, P., Yongxing, J. Risk assessment of potential catastrophic accidents for transportation of special nuclear materials through Turkish Straits. Energy Policy 56, 126-135. (2013).

20. Pykhtin, K., Simankina. Risk-based approach in valuation of workplace injury rate for transportation and construction industry. In IOP Conference Series: Earth and Environmental Science (2017).

21. Titov, A., Tumanov, A.: Autonomous safety system for MSW landfills. E3S Web of Conferences, vol. 161. (2020).

22. Tumanov, A ., Gumenyuk, V.: Development of advanced mathematical predictive models for assessing damage avoided accidents on potentially-dangerous sea-based energy facility. IOP Conference Series: Earth and Environmental Science, vol. 90(1). (2017).

23. Kulinkovich, A., Sakova, N.: Development of the Express Method for Controlling Uranium Compounds in Natural Waters in Emergency Situations on Floating Nuclear Thermal Power Plants. IOP Conference Series: Earth and Environmental Science, vol. 272(2). (2019). 